\title{
NASA's Radioisotope Power Systems Program Status
}

\author{
Leonard A. Dudzinski ${ }^{1}$ \\ NASA Headquarters, Washington, DC, 20546 \\ John A. Hamley ${ }^{2}$, Peter W. McCallum ${ }^{3}$, Thomas J. Sutliff ${ }^{4}$, and June F. Zakrajsek ${ }^{5}$ \\ NASA Glenn Research Center, Cleveland, $\mathrm{OH} 44135$
}

\begin{abstract}
NASA's Radioisotope Power Systems (RPS) Program began formal implementation in December 2010. The RPS Program's goal is to make available RPS for the exploration of the solar system in environments where conventional solar or chemical power generation is impractical or impossible to meet mission needs. To meet this goal, the RPS Program manages investments in RPS system development and RPS technologies. The current keystone of the RPS Program is the development of the Advanced Stirling Radioisotope Generator (ASRG). This generator will be about four times more efficient than the more traditional thermoelectric generators, while providing a similar amount of power. This paper provides the status of the RPS Program and its related projects. Opportunities for RPS generator development and targeted research into RPS component performance enhancements, as well as constraints dealing with the supply of radioisotope fuel, are also discussed in the context of the next ten years of planetary science mission plans.
\end{abstract}

\section{Nomenclature}

$\begin{array}{ll}A C U & =\text { ASRG Control Unit } \\ A O & =\text { Announcement of Opportunity } \\ A S C & =\text { Advanced Stirling Convertor } \\ A S R G & =\text { Advance Stirling Radioisotope Generator } \\ \text { Avg } & =\text { Average } \\ B O M & =\text { Beginning of Mission } \\ D O E & =\text { Department of Energy } \\ D U F F & =\text { Demonstration Using Flattop Fissions } \\ G P H S & =\text { General Purpose Heat Source } \\ G R C & =\text { Glenn Research Center } \\ J P L & =\text { Jet Propulsion Laboratory } \\ M H W & =\text { Radioisotope Thermoelectric Generator } \\ M M L A E & =\text { Multi-Mission Launch Approval Engineering } \\ M M R T G & =\text { Multi-Mission Radioisotope Thermoelectric Generator } \\ M S L & =\text { Mars Science Laboratory } \\ P I & =\text { Principal Investigator } \\ P P \& A & =\text { Program Planning and Assessment } \\ P S D & =\text { Planetary Sciences Division } \\ P u-238 & =\text { plutonium-238 } \\ R P S & =\text { Radioisotope Power Systems } \\ R T G & =\text { Radioisotope Thermoelectric Generator } \\ T A P & =\text { Technology Advancement Project }\end{array}$

${ }^{1}$ Program Executive, RPS Program, 300 E Street. SW/MS Suite 3X63, AIAA Senior Member

${ }^{2}$ Program Manager, RPS Program Office, 21000 Brookpark Road, MS 142-5, AIAA Senior Member

${ }^{3}$ Program Control Manager, RPS Program Office, 21000 Brookpark Road, MS 142-5

${ }^{4}$ Deputy Program Manager, RPS Program Office, 21000 Brookpark Road, MS 142-5, AIAA Member

${ }^{5}$ Program Planning and Assessment Manager, RPS Program Office, 21000 Brookpark Road, MS 142-5 
$W_{e} \quad=$ Watts (electrical)

\section{Introduction}

$\mathrm{R}$ ADIOISOTOPE Power Systems have made possible many missions to locations where the Sun's intensity is either too dim, obscured, or otherwise inadequate for conventional power generation. These RPS have enabled scientists to collect data that have rewritten textbooks and revised our collective understanding of the solar system. In 2010, NASA Headquarters, recognizing the unique capabilities offered by radioisotope-powered missions, formed a single program office, which consolidates the management of systems and technologies to enable more frequent and diverse applications of RPS to future planetary science missions. ${ }^{1}$

The RPS Program manages the NASA Science Mission Directorate's investments in radioisotope power systems and their deployment to future missions. The RPS Program is responsible for acquisition and development of thermal energy conversion technologies and related system technologies, as well as acquisition and development of flight radioisotope power systems by the Department of Energy (DOE) for future NASA mission uses. The RPS Program provides a steady, integrated knowledge basis for mission applications of RPS ranging from Discovery-class PI-led missions to large flagship missions. Through ongoing program management, the technical expertise and processes developed in support of one mission application can be transferred and reapplied efficiently to subsequent missions.

In the first years of the RPS Program's inception, the focus has been on flight and flight system developments. The newest RPS, which leverages generator technology from previous RPS missions, is the Multi-Mission Radioisotope Thermoelectric Generator (MMRTG). The MMRTG was developed and successfully deployed as part of the Mars Science Laboratory (MSL) mission and is now operating smoothly on the surface of Mars powering Curiosity.

The RPS Program has been collecting lessons learned from team members of current radioisotopepowered missions and is developing a database of key information that can be used to benefit future RPS development. Over eight different lessons learned sessions have been collected from the Applied Physics Laboratory of The John Hopkins University on the lessons learned during the Pluto New Horizons Mission and from the Jet Propulsion Laboratory for the Mars Science Laboratory. Lessons collected included technical lessons as well as management and communication lessons.

The future system, currently under development by the Department of Energy in conjunction with the RPS Program, is the Advanced Stirling Radioisotope Generator (ASRG). This system has successfully completed its final design review, and the RPS Program is proceeding with the development of a fueled qualification unit and two unfueled flight units by no earlier than 2016. The ASRG was offered on the recent Discovery 12 Announcement of Opportunity (AO), with two of the three finalists proposing to utilize it. This paper will provide an update on the RPS Program and discuss the recent past, status, and future opportunities presented by RPS.

\section{Radioisotope Power Program Overview}

Radioisotope Power Systems (RPS) have enjoyed highly successful use in U.S. space exploration, having supplied reliable power for 27 missions over more than five decades. NASA, in partnership with the Department of Energy (DOE), has deployed RPS on breathtaking missions to the Moon, Mars, and the outer planets (with a mission to Pluto on the way). These systems all have employed the same technological energy conversion heritage as used originally in 1961 and have served our exploration needs well. ${ }^{2}$ RPS will continue to be critical for power generation on space science missions where the use of other means of energy conversion, such as solar arrays, is impractical because of diminished intensity of the sun due to distance from or shadowing of the sun's light, or some other specific mission need.

Historically, the one form of energy conversion-thermoelectric energy conversion-has enabled many missions. Eight basic Radioisotope Thermoelectric Generator (RTG) configurations have been flown in space by the United States. The latest RTG configuration, the Multi-Mission RTG (MMRTG), was flight qualified, launched, and is providing power for the Mars Curiosity rover, with performance as predicted.

While all configurations of radioisotope power systems flown to date have been based on thermoelectric energy conversion, investments in other energy conversion research have also been made. Dynamic power conversion methods have been studied for application in radioisotope power systems, showing promise of efficiency gains, although NASA has not yet flown such a system. Other investments in energy conversion 
technologies have been made to identify and improve performance of particular approaches of both static and dynamic methods. $3,4,5$

In 2010, NASA established the RPS Program. ${ }^{1}$ The Program is chartered to provide flight systems, develop supporting technologies and promote operational efficiencies. The Program is organized to meet the objectives provided in Table 1. These objectives address the top-level requirements on behalf of the NASA

Table 1. RPS Program Objectives

\begin{tabular}{|l|l|}
\hline Number & Objective \\
\hline OBJ-1 & $\begin{array}{l}\text { Increase the availability and capabilities of radioisotope power systems to cost-capped and } \\
\text { directed missions through acquisition of new RPS. }\end{array}$ \\
\hline OBJ-2 & $\begin{array}{l}\text { Reduce NEPA and Launch Safety Approval schedule risk to help keep it off the mission } \\
\text { critical path. }\end{array}$ \\
\hline OBJ-3 & $\begin{array}{l}\text { In the near term, complete the development of the Advanced Stirling Radioisotope Generator } \\
\text { to be available for integration at the launch site with sufficient lead-time to meet a first } \\
\text { mission system launch date. }\end{array}$ \\
\hline OBJ-4 & $\begin{array}{l}\text { Acquire and sustain RPS capabilities and infrastructure and coordinate support between } \\
\text { implementing missions as a means to maintain a repository of corporate knowledge and } \\
\text { lessons learned. }\end{array}$ \\
\hline OBJ-5 & $\begin{array}{l}\text { Evaluate, research, and develop new component technologies for deep space power systems } \\
\text { that will enable the next generation of spacecraft for NASA missions. }\end{array}$ \\
\hline
\end{tabular}

Science Mission Directorate and are linked to metrics that are an indication of Program effectiveness.

The RPS Program is organized as a cohesive multi-organization effort, integrating strengths from the Department of Energy, the Jet Propulsion Laboratory, the Johns Hopkins Applied Physics Laboratory, NASA Glenn Research Center and NASA Goddard Space Flight Center. The Program contains two projects: the ASRG Flight Project managed by the DOE and the Technology Advancement Project managed by NASA GRC.

Within the Program, several elements conduct activities critical to meeting NASA's technical requirements. Two of the more unique elements are Multi-Mission Launch Approval Engineering (MMLAE) and Program Planning and Assessment (PP\&A). MMLAE activities are managed by JPL and produce products required for all mission launch approval, such as launch vehicle data books, to reduce the burden on any individual mission, facilitate an RPS mission to fit on a shorter timeline, and streamline the launch approval process timeframe for PI-led missions to the greatest extent possible.

One key objective of the work of the program office is to enable the application of RPS on these PI-led competed missions, such as Discovery and New Frontiers, by acting on their behalf before any Announcement of Opportunity (AO) is released. This is required due to the long development cycle of preparing to consider using an RPS compared to other spacecraft subsystems.

PP\&A develops and maintains the implementation strategy of the RPS Program to meet the Level I requirements and stakeholder expectations. This element is responsible for the following major functions: mission analysis, systems analysis, program assessment, stakeholder integration, sustainability assessment, acquisitions, and road mapping.

The Technology Advancement Project (TAP) has been tasked with conducting low-to-mid Technology Readiness Level (TRL) improvements in energy conversion so that future RPS may be enabled by the investments. TAP uses the inputs from the PP\&A mission and systems analyses, along with stakeholder inputs, to determine the content of the project. The project is a formal NASA portfolio project, governed by NPR 7120.8. This project has two major roles: (1) the development of new RPS technologies and (2) the sustainment of critical technological capabilities required to ensure a national capability in the production of the fundamental electrical power generating components of an RPS. This latter role is a program-delegated role implemented by TAP as a natural fit with its skills.

The RPS Program has been structured to have separate flight projects for each investment that would develop a new flight RPS. Currently there is one project, the ASRG Flight project managed by the DOE. Flight RPS are fueled and delivered solely by the DOE as required by statute, and are governed by a Memorandum of Understanding signed by both agencies. ${ }^{6}$ These flight projects are implemented as stand-alone projects. For 
copies of currently available flight systems, whether to replace "on-the-shelf" availability of systems or directly in support of a specific mission, a stand-alone flight project would not be implemented. For these recurring investments, since minimum RPS Program involvement is expected, a task would be implemented at the Program level and would be coordinated directly with the DOE and the mission if required.

\section{General Guidelines}

Planetary missions have returned an abundance of data and images that, when analyzed, have in many cases re-written scientific textbooks. The results of NASA planetary exploration have vastly improved our understanding of the universe and the development and evolution of Earth. The diversity of these missions and their rich scientific discoveries were made practical only by the use of radioisotope power.

Currently, there are four deployed RPS missions: Voyager 1\& 2, Cassini, New Horizons, and Mars Science Laboratory. Each of these missions has unique objectives that are addressing fundamental scientific questions regarding our solar system. ${ }^{7}$ Each of these missions is powered by an RTG.

Table 2 provides a top-level compilation of each mission, its primary objective, the launch date, the current mission stage, and key power generation parameters. Pictures of the three different generations of power systems, the MHW-RTG, GPHS-RTG and MMRTG, are provided in Fig. 1.

Table 2. Summary of missions using RPS.

\begin{tabular}{|c|c|c|c|c|c|c|}
\hline Mission & $\begin{array}{l}\text { Primary } \\
\text { Objective }\end{array}$ & $\begin{array}{l}\text { Launch } \\
\text { Date }\end{array}$ & $\begin{array}{c}\text { Science } \\
\text { Mission } \\
\text { Duration }\end{array}$ & $\begin{array}{c}\text { Mission } \\
\text { Stage }\end{array}$ & $\begin{array}{c}\text { Power } \\
\text { Generator } \\
\text { Type } \\
\text { (Quantity) }\end{array}$ & $\begin{array}{c}\text { Power } \\
\text { Generator } \\
\text { Parameters }\end{array}$ \\
\hline $\begin{array}{l}\text { Voyager } \\
1 \& 2\end{array}$ & $\begin{array}{l}\text { Explore the solar } \\
\text { system beyond } \\
\text { the neighborhood } \\
\text { of the outer } \\
\text { planets to the } \\
\text { outer limits of the } \\
\text { Sun's sphere of } \\
\text { influence, and } \\
\text { possibly beyond. }\end{array}$ & $\begin{array}{l}\text { August } \\
20,1977 \\
\text { September } \\
5,1977\end{array}$ & $\begin{array}{l}35+ \\
\text { years }\end{array}$ & $\begin{array}{l}\text { Extended } \\
\text { Operations }\end{array}$ & MHW-RTG (3) & 474 We BOM \\
\hline Cassini & $\begin{array}{l}\text { Explore the } \\
\text { Saturnian system } \\
\text { from orbit: the } \\
\text { planet and its } \\
\text { atmosphere, rings } \\
\text { and } \\
\text { magnetosphere, } \\
\text { and its moons, } \\
\text { particularly Titan } \\
\text { and the icy } \\
\text { satellites. }\end{array}$ & $\begin{array}{l}\text { October } \\
15,1997\end{array}$ & $\begin{array}{l}7 \text { year } \\
\text { cruise, } \\
\sim 8+\text { year } \\
\text { science }\end{array}$ & $\begin{array}{l}\text { Extended } \\
\text { Operations }\end{array}$ & GPHS-RTG (3) & 885 We BOM \\
\hline $\begin{array}{l}\text { New } \\
\text { Horizons }\end{array}$ & $\begin{array}{l}\text { The first close-up } \\
\text { study of Pluto and } \\
\text { its moons and } \\
\text { other icy worlds } \\
\text { in the distant } \\
\text { Kuiper Belt. }\end{array}$ & $\begin{array}{l}\text { January } \\
19,2006\end{array}$ & $\begin{array}{l}9.5 \text { year } \\
\text { cruise, } \\
5 \text { year } \\
\text { science }\end{array}$ & Cruise & GPHS-RTG (1) & 243 We BOM \\
\hline $\begin{array}{l}\text { Mars } \\
\text { Science } \\
\text { Laboratory }\end{array}$ & $\begin{array}{l}\text { Assess whether } \\
\text { Mars ever had an } \\
\text { environment able } \\
\text { to support small } \\
\text { life forms called } \\
\text { microbes. }\end{array}$ & $\begin{array}{l}\text { November } \\
26,2011\end{array}$ & $\sim 2$ year & $\begin{array}{l}\text { In Initial } \\
\text { Operations }\end{array}$ & MMRTG (1) & 110 We BOM \\
\hline
\end{tabular}

American Institute of Aeronautics and Astronautics 


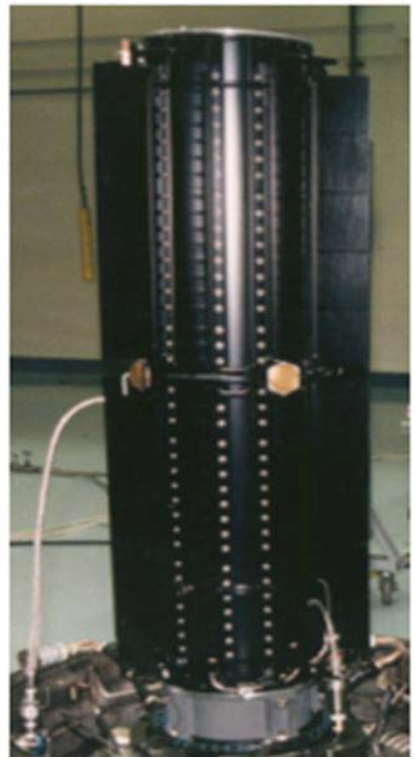

1a) MHW-RTG

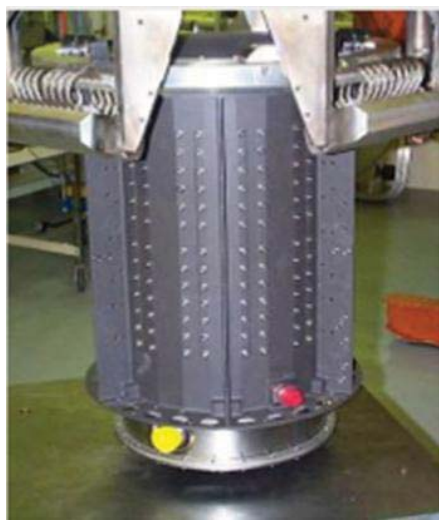

2a) GPHS-RTG

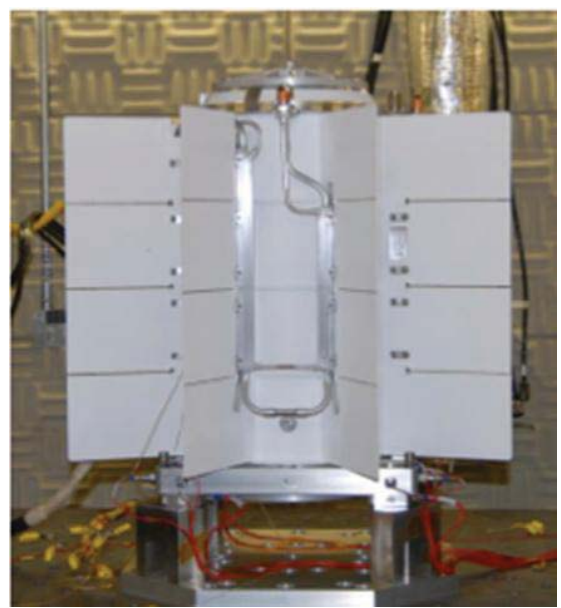

3a) MMRTG

Figure 1. RPS currently being flown.

For each of these missions, the performance of the RPS is analyzed against model predictions. Key electrical and thermal RPS performance data are received via telemetry and used for this analysis. These prediction models account for environmental effects, power generator degradation effects and the natural decay of their Pu-238 fuel. These models are used to assess power generation condition and are used to project future power availability. Mission planners assess the feasibility of the future mission power needs using these data. Table 3 provides a summary of the measured value of generator power and the predicted

Table 3. Predicted Power and Actual Power for current RPS Missions.

\begin{tabular}{|l|l|l|l|l|}
\hline Mission & Generator & $\begin{array}{l}\text { Predicted } \\
\text { (last prediction } * \text { ) }\end{array}$ & Actual & $\begin{array}{l}\text { Persistence of } \\
\text { actuals }\end{array}$ \\
\hline Voyager 1 & 1 & $266.4 \mathrm{~W}_{\mathrm{e}}$ & $265.0 \mathrm{~W}_{\mathrm{e}}$ & August, 2012 \\
\hline Voyager 2 & 1 & $269.2 \mathrm{~W}_{\mathrm{e}}$ & $267.5 \mathrm{~W}_{\mathrm{e}}$ & May, 2012 \\
\hline Cassini & $1,2, \& 3$ & $648.8 \mathrm{~W}_{\mathrm{e}}$, avg & $647.6 \mathrm{~W}_{\mathrm{e}}$, avg & December, 2013 \\
\hline $\begin{array}{l}\text { Pluto New } \\
\text { Horizons }\end{array}$ & 1 & $\begin{array}{l}212 \mathrm{~W}_{\mathrm{e}}(\mathrm{DOE} \text { Prediction } \\
\text { at launch) }\end{array}$ & $213 \mathrm{~W}_{\mathrm{e}}$ & January, 2013 \\
\hline $\begin{array}{l}\text { Mars Science } \\
\text { Lab }\end{array}$ & 1 & $112 \mathrm{~W}_{\mathrm{e}}$ avg (quarterly) & $111.8 \mathrm{~W}_{\mathrm{e}}$, avg & January, 2013 \\
\hline
\end{tabular}


value of generator power per RPS mission. Each mission collects and provides the data necessary to operate and manage a successful mission. ${ }^{8}$ The RPS Program, by collecting all of the RPS mission data, can look across the missions and the RPS systems to identify trends, potential gaps, and lessons learned, thus providing a "living history" that can benefit future missions

\section{A. MMRTG Status}

The newest operational RPS is the MMRTG. The RPS Program maintained an engineering awareness of the MSL MMRTG development. Post MSL launch, the Program acquired and archived key MMRTG data. The Program currently receives periodic RPS performance information from the mission. The MMRTG is based on the proven RPS design used to provide electrical power for NASA's two earlier Viking landers, which operated on the surface of Mars for 40 months and more than six years, respectively. This unit, shown in cutaway in Fig. 2, converts the heat from the radioactive decay of plutonium-238 in eight General Purpose Heat Source (GPHS) modules to produce nominal $110 \mathrm{We}$ of electric power for use on the Jeepsized rover.

The RPS Program is currently funding the construction two additional MMRTGs by the DOE for future NASA missions. The second flight unit is completed and unfueled and the third flight unit will be completed in late 2013. These generators will be available to future planetary missions.

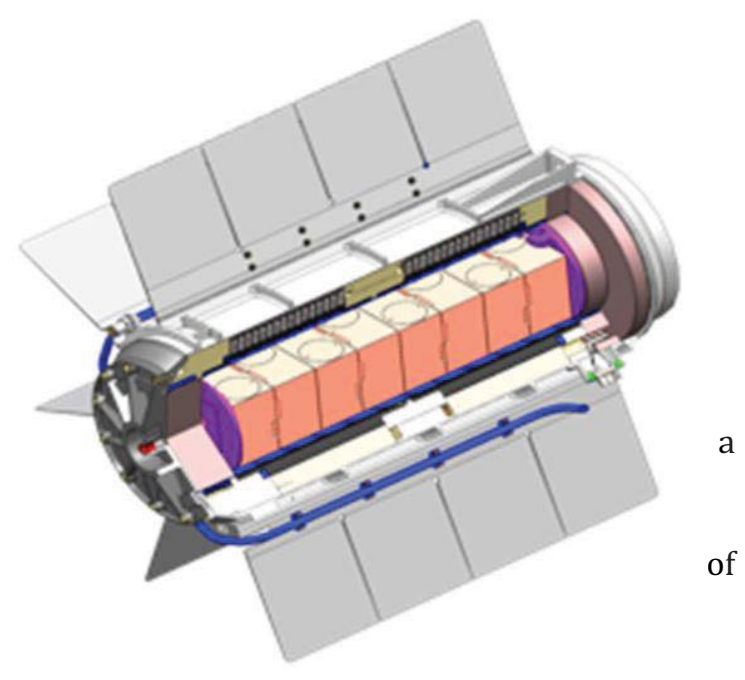

Figure 2. Cutaway view of the MMRTG.

\section{B. ASRG Status}

Much like the MMRTG, the ASRG produces electrical power from the heat output of radioisotope fuel. A cutaway drawing of the ASRG appears in Fig. 3. An ASRG utilizes Stirling engines to generate alternating current electrical power from the heat of two GPHS modules. The Advanced Stirling Convertors (ASCs) are

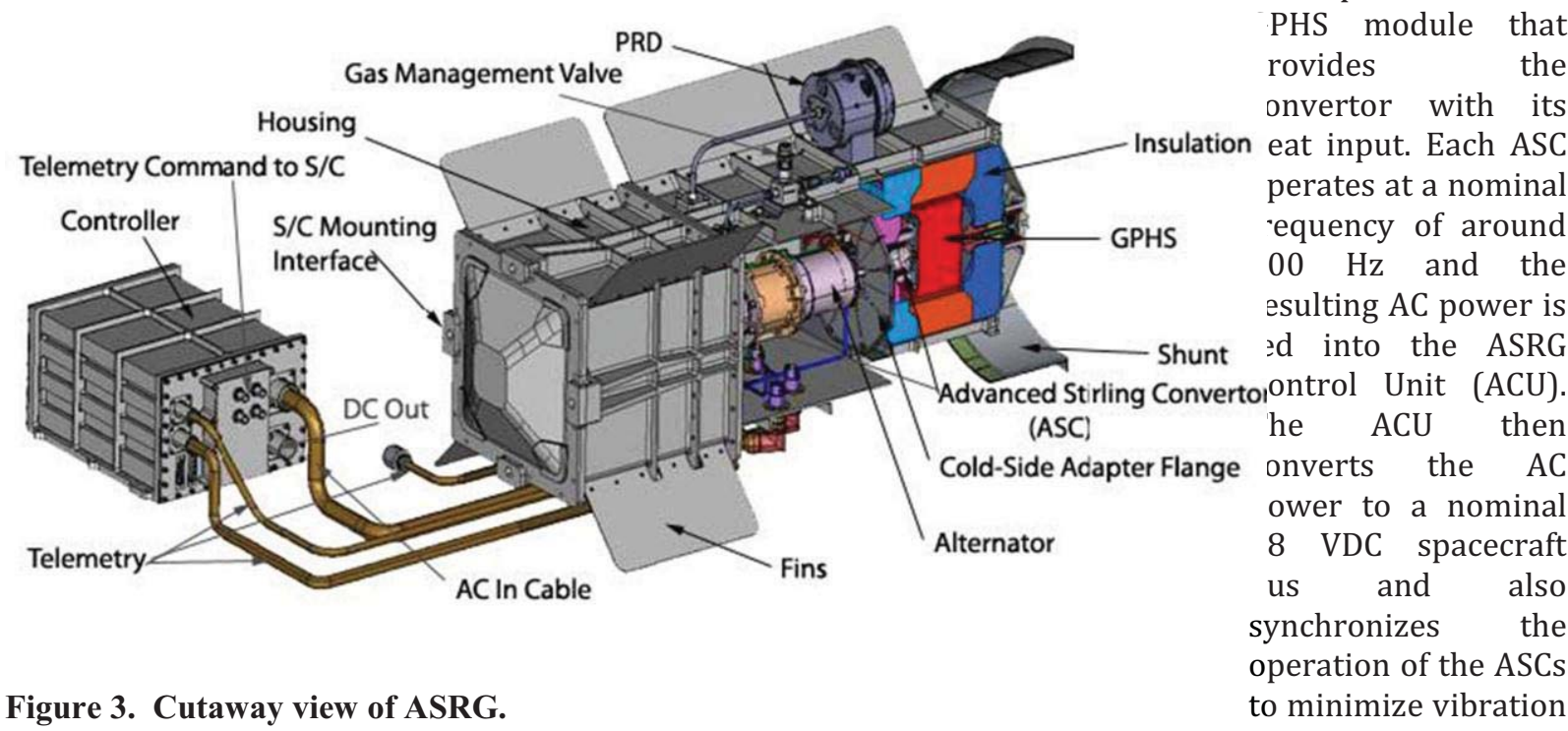
inputs to the spacecraft. The ASRG power conversion efficiency is on the order of 30 percent and as a result utilizes less plutonium-238 to produce a given power level compared to thermoelectric energy conversion (which is around 7 percent efficient). 
The DOE manages the ASRG Flight Project for the RPS Program. The DOE and their system integrator, Lockheed Martin, are designing and developing a qualification unit and two flight units. The Stirling converters have been designed and built by Sunpower Inc. with input from NASA GRC. The ASRG flight system development phase was initiated with NASA requirements established through mission studies and workshops, and a formal supplement to the NASA-DOE Memorandum of Understanding governing the development of radioisotope power systems was baselined in May 2012. The project has completed its final design, and has begun fabrication of flight hardware. The Final Design Review (FDR) and delta FDR resolved

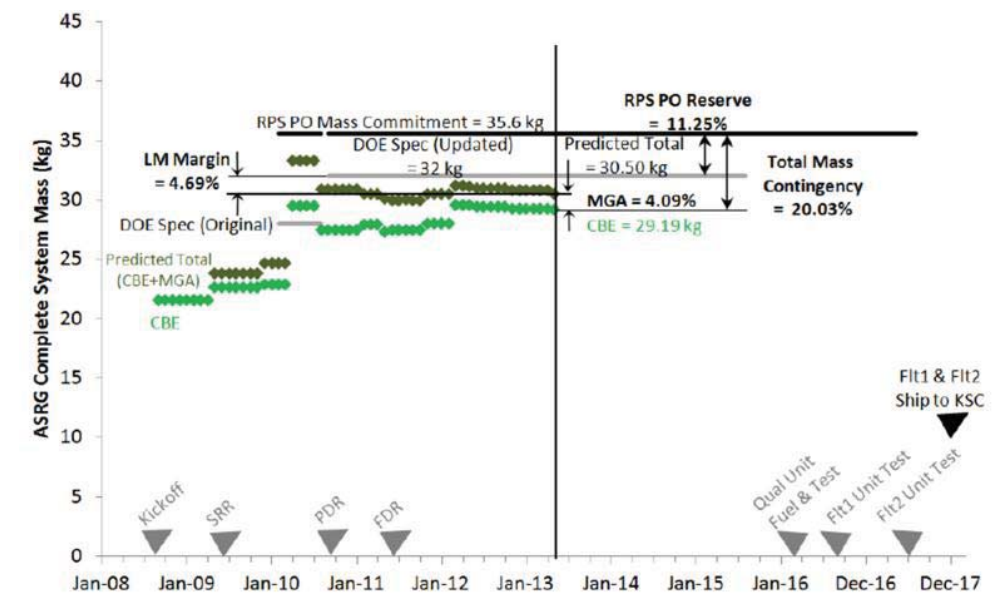

a) ASRG System Mass

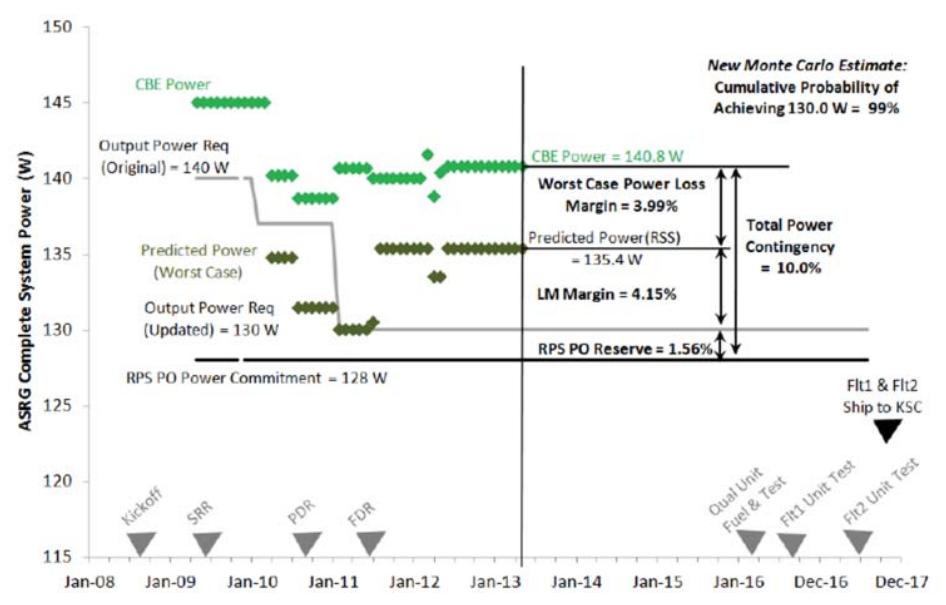

b) ASRG System Power

Figure 4 ASRG Technical Performance Metrics that would land a floating platform on Titan's mission that would rendezvous and land repeatedly at comet Wirtanen. Neither of these missions were selected, resulting in no near-term mission assignment for the ASRG. However, NASA is dedicated to providing the ASRG to power future missions that may benefit from this enabling and enhancing technology. Therefore, the two unfueled flight ASRGs and one qualification unit are being prepared for delivery to Idaho National Laboratory (INL) by no earlier than October 2016. The qualification unit will be fueled and tested by INL and then placed on long-duration testing to increase system reliability evidence. This testing and flight hardware availability will facilitate future competed missions in the Discovery or New Frontiers programs, or missions directed specifically by NASA. resulted in the project management team being restructured. Flight ASCs, critical path item, are being built; the Generator Housing Assembly GHA for the qualification unit is complete; and, the ACU demonstrated qualification-level vibration control of the convertors, confirming system level control and capability. Figure 4a and $4 \mathrm{~b}$ provide the status of the mass and power technical performance metrics, and Fig. 5 provides the current reliability estimate. These estimates are stable and have adequate margin against the requirements.

The ASRG was integrated into two of the three Discovery 12 Announcement of Opportunity (AO) Step 2 proposals. The two RPSenabled mission concepts were the Titan Mare Explorer, a mission to Saturn's moon Titan

open technical issues and

.




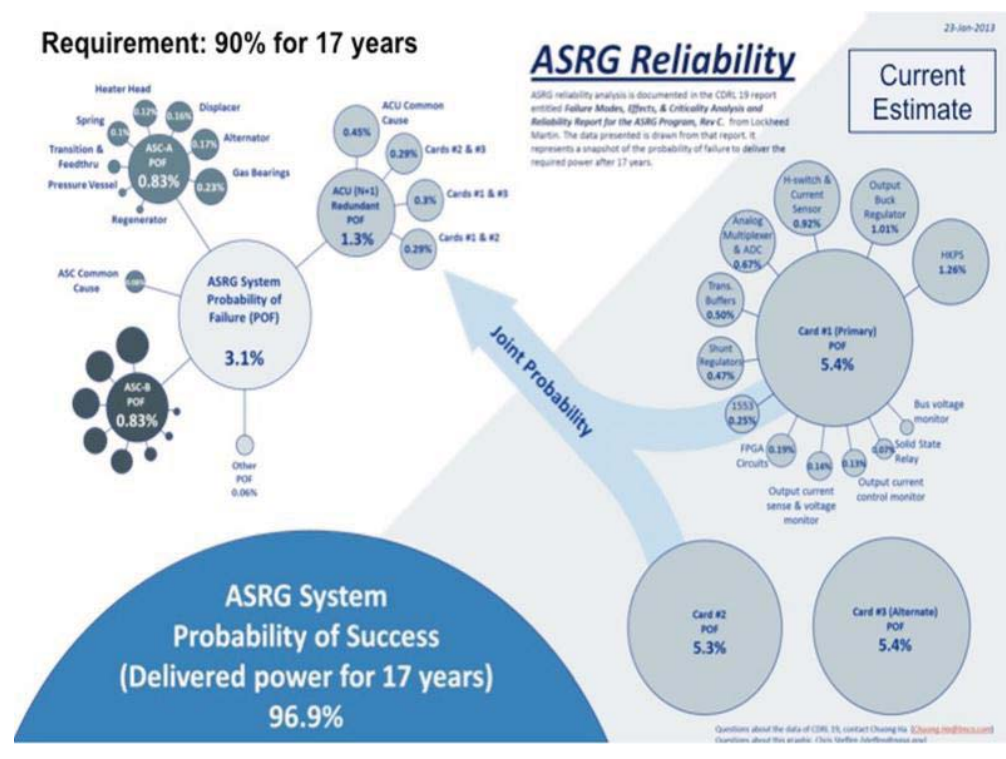

IV. Program Performance

In 2009, during Program formulation activities, the RPS Program articulated a list of five-year goals. At the four-year point, seven of the eight have been achieved. These goals relate to the Program's ability to demonstrate leadership in areas that lead to efficient processes, hardware availability and technology advancement. Table 4 lists the status of the five-year goals.

The RPS Program leadership has been successful at making significant and measureable progress on all of these goals. In one of the eightinvestments in new technologiesselections for a next round have been made but have not been fully funded due to national fiscal constraints. NASA currently has an MMRTG on the shelf

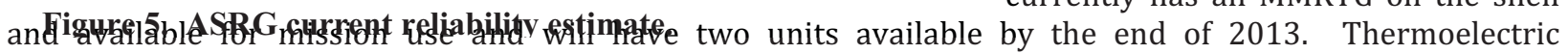
technology investments have resulted in new materials and thermocouples that are being considered for a next-generation RTG. ${ }^{9}$ This system would use the same basic system design as the MMRTG but would infuse new couple technology that is projected to result in a $45-63 \%$ increase in power generation at the BOM.

$\mathrm{Pu}-238$ has been identified as a valuable and limited resource that can enable and enhance NASA planetary goals and objectives. Although it is the responsibility of DOE, not NASA, to maintain the national inventory of Pu-238, the RPS Program has established a clear process to estimate future mission needs that, in turn, allows the DOE to identify and track the Pu-238 that would be needed to fulfill the projected mission requirements. This capability Table 4. Status of RPS Program's five-year goals. Established 2009.

\begin{tabular}{|l|}
\hline \multicolumn{1}{|c|}{ RPS Program Five-Year Goals } \\
\hline RPS Program providing strategic leadership \\
\hline Multiple RPS systems supporting NASA missions - e.g. MMRTG and \\
ASRG \\
\hline $\begin{array}{l}\text { Strategic investments resulting in launch approval processes } \\
\text { staying off critical path }\end{array}$ \\
\hline Standard established for flight qualifying RPS \\
\hline Next RPS technology ready for maturation \\
\hline Next round of new technologies for investment selected \\
\hline Formal processes in place to track NASA's Pu-238 needs \\
\hline DOE well on its way to producing Pu-238 again \\
\hline
\end{tabular}

quantify and prepare PSD RPS requirements in strategic support of future missions. The RPS Program supports the RPS Program Executive at NASA Headquarters in working with the DOE to re-establish domestic Pu-238 production. In 2013, several important initial steps in demonstration of the process required for the re-establishment of a production capability were successfully demonstrated.

\section{A Look Ahead}

The RPS Program is well positioned to build upon its initial successes and amplify its support of future NASA planetary science exploration. ASRG should be completed and available for mission use by no earlier than 2016. In lieu of a selected mission that would use the ASRG, additional test data will be collected to provide detailed assessment and information useful to future missions. One of the available MMRTG flight units is baselined for use in the next Mars rover mission being proposed for launch in 2020. Some 
sustainment of industry is necessary to maintain these highly specialized and complex technologies. In order to take best advantage of the current maturity of the thermoelectric technology investments, plans are underway to transfer NASA-developed technology to industry, specifically Teledyne Energy Systems Inc. Given the availability of budget appropriation and successful technology transfer by mid-decade 2010, a more efficient RTG flight unit could be available for mission use early in the 2020s. Using mission studies and system studies that have been completed by the RPS Program as well as the 2011 Planetary Science Decadal Survey design reference missions, technology development and demonstrations supportive of larger-class power systems in the range of 500 to 600 We are being planned. ${ }^{10}$ Building off the successful DUFF experiment that demonstrated electrical power generation from Stirling converters coupled to a uranium235 fission heat source via a 0.6 meter stainless steel and water heat pipe, consideration is being given to a joint endeavor between STMD and PSD in a kilowatt-class fission prototype test using current infrastructure. ${ }^{11}$

\section{Summary}

The RPS Program was approved for implementation by NASA Headquarters in 2010. The overarching goal of the Program is to make available RPS for the exploration of the solar system in environments where conventional solar or chemical power generation is impractical or impossible, or where it would significantly enhance the capabilities of a mission. In the past three years, the Program has established the critical leadership and partnerships to meet all but one of the identified goals, indicative of Program success. This has been accomplished by working in partnership with the DOE to mature the ASRG design, and begin to build flight hardware and demonstrate system-level control of power generation; building and having available one, soon to be two, MMRTG flight systems waiting to meet future mission needs; and initiating thermoelectric technology transfer to industry supporting future higher efficient RPS flight system development. The Program continues to execute the tasks necessary to continue achieving the established goals by maintaining a strong top-level focus on meeting planetary science needs now and in the future. The RPS program provides the power to explore.

\section{References}

${ }^{1}$ NASA's Radioisotope Power Systems and Technologies - A Forward Look. Leonard A. Dudzinski, John A. Hamley, Thomas J. Sutliff, June F. Zakrajsek, AIAA-2011-5868, 2011.

${ }^{2}$ Worth, H. E., and Warren, M., "TRANSIT TO TOMORROW Fifty Years of Space Research at the Johns Hopkins University applied Physics Laboratory, 1st ed., Johns-Hopkins University Applied Physics Laboratory, Baltimore, 2009.

${ }^{3}$ Sutliff, Thomas J., and Leonard A. Dudzinski. "NASA Radioisotope Power System Program-Technology and Flight Systems." AIAA-2009-4575, 2009.

${ }^{4}$ Fleurial, Jean-Pierre. "Thermoelectric power generation materials: Technology and application opportunities." JOM 61.4 (2009): 79-85.

${ }^{5}$ Wong, Wayne A., and Peggy A. Cornell. "Advanced Stirling Convertor (ASC) Technology Maturation in Preparation for Flight." (2012).

6 "MOU Between the DOE and the NASA Concerning Radioisotope Power Systems for Space Missions", July $26,1991$.

${ }^{7}$ The Solar System Exploration Roadmap, URL:

http://solarsystem.nasa.gov/multimedia/downloads/SSE RoadMap 2006 Report FC-A med.pdf, [cited June 2013].

${ }^{8}$ The Mars Science Laboratory (MSL) MMRTG In-Flight: A Power Update, David Woerner, Victor Moreno, Loren Jones, Robert Zimmerman and Eric Wood (NASAJPL)

${ }^{9}$ Fleurial J. P., Bux S. K. Li B. C. Y., Huang C. K., Cheng B. J. Vo T., VonAllmen P., Caillat T., Pei Y., Lalonde A., Snyder G. J., King D., Star K., Ma J., Kaner R. B., Dunn B. S., Cox C., Kauzlarich S. M., "Progress Towards High Efficiency Thermoelectric Materials for Space Power',NETS-2012.

${ }^{10}$ Committee on the Planetary Science Decadal Survey, National Research Council, "Vision and Voyages for Planetary Science in the Decade 2013-2022," The National Academies Press, Washington, DC, 2011.

${ }^{11}$ The DUFF Experiment - Why and How, David D. Dixon, et al, NETS-2013. 